\title{
Editorial: Advanced Corrosion Wear Resistant Alloys and their Characterization for High-Temperature Applications
}

\author{
Liujie $\mathrm{Xu}^{1 *}$, Shengqiang $\mathrm{Ma}^{2 *}$ and Hanguang $\mathrm{Fu}^{3}$ \\ ${ }^{1}$ National Joint Engineering Research Center for Abrasion Control and Molding of Metal Materials, Henan University of \\ Science and Technology, Luoyang, China, ${ }^{2}$ State Key Laboratory for Mechanical Behavior of Materials, Xi'an Jiaotong \\ University, Xi'an, China, ${ }^{3}$ School of Materials Science and Engineering, Beijing University of Technology, Beijing, China
}

Keywords: wear-resistant materials, microstructure, hardness, high temperature, corrosion

\section{Editorial on the Research Topic}

Advanced Corrosion Wear Resistant Alloys and their Characterization for High-Temperature Applications

Wear is one of the failure modes of material damage, and it is of importance to the study of mechanical equipment destruction. Statistics show that about $80 \%$ of machine parts are destroyed due to wear of these industrial components, and the annual economic loss caused by friction and wear accounts for about 5\% of GDP (Chen, 2012). Wear-resistant materials have gradually

OPEN ACCESS

Edited and reviewed by: John L. Provis,

University of Sheffield, United Kingdom

*Correspondence:

Liujie Xu

wmxlj@126.com

Shengqiang Ma

sqma@mail.xitu.edu.cn

Specialty section:

This article was submitted to

Structural Materials,

a section of the journal

Frontiers in Materials

Received: 16 January 2020 Accepted: 26 February 2020 Published: 03 April 2020

Citation:

Xu L, Ma S and Fu H (2020) Editorial: Advanced Corrosion Wear Resistant Alloys and their Characterization for High-Temperature Applications. been developed with the advancement of human society. They originate from the Stone Age, the Bronze Age, the Iron Age, and the era of modern industrial revolution (Wei and Xu, 2019). Until now, wear-resistant materials have been widely applied in many fields, including in machinery, metallurgy, electric power, building materials, national defense, railway, coal, chemical industry, and others (Padture et al., 2002; Xu et al., 2017). The development of high-performance wear- and corrosion-resistant materials promotes huge economic and social benefits (Zhang and Chen, 2015; Xu et al., 2017).

This Research Topic focuses on the design, control, and characterization of wear-resistant materials. It includes corrosion and oxidation at interfaces, formation mechanisms of corrosion/wear-resistant surface films, microstructural design of dual-phase alloys, and synergistic corrosion properties tailored to the unique interface structure with specific chemical, physical, or mechanical requirements. The topic also includes state-of-the-art characterization techniques of the materials (e.g., XPS, SEM, EBSD, TEM, etc.) to assess property degradation. Finally, the Research Topic has been collected and organized in the form of eight relevant articles from 73 contributors to the relevant fields. We hope that the topic can provide a close platform for researchers engaging in research into wear-resistant materials.

Li B. et al. investigated the mechanical, tribological, and oxidation resistance properties of NiCrAlY coating produced by atmospheric plasma spraying. The heat treatment could effectively increase the microhardness and adhesive strength as well as decrease the porosity of the coating. The coating presented the highest adhesive strength of $62.1 \mathrm{MPa}$ and the lowest porosity of $3.06 \%$ as well as excellent tribological properties and oxidation resistance at $900^{\circ} \mathrm{C}$ after $1,100^{\circ} \mathrm{C}$ heat treatment.

Zhang et al. presented a study on the effect of tempering temperature on impact wear behavior of $30 \mathrm{Cr} 3 \mathrm{Mo} 2 \mathrm{WNi}$ hot-working die steel. A secondary hardening with maximum hardness, 48.6 HRC, was achieved at a tempering temperature of $550^{\circ} \mathrm{C}$. Also, the fatigue delamination was the 
main damage mechanism during the impact wear, and three typical damage features were identified and found to have different tempering temperatures.

Guo et al. adopted ball-block friction pairs to qualitatively study the influence of a twin carbide structure of different degrees on the friction and wear performance of G95Cr18 stainless bearing steel, and found that a slight twin carbide structure had only a small effect on the friction coefficient but could reduce the wear rate slightly, while a severe twin carbide structure could significantly increase the friction coefficient and wear rate. Thus, the existence of an optimal value for a twin carbide structure was confirmed.

Wang et al. studied the effects of carbon contents on microstructure evolution, mechanical properties, and abrasive impact wear resistance behavior of $\mathrm{Cr}-\mathrm{Si}-\mathrm{Mn}$ low alloy cast steels. The increase of carbon content resulted in a gradual microstructural change from lath martensite into acicular martensite. The hardness increased, and impact toughness decreased distinctly due to increasing carbon supersaturation and refinement of martensite. The wear resistance increased first, and it then decreased because of the wear mechanism changing from plastic fatigue wear to brittle fracture wear.

Liu and Chen studied the dynamic recrystallization (DRX) behavior of $316 \mathrm{LN}$ austenitic stainless steel by hot compression experiments. It was found that twinning played a significant role in the nucleation and growth of DRX. The nucleation of DRX in $316 \mathrm{LN}$ steel was characterized by bulging of serrated grain boundaries. Twining took place near the serrated grain boundary in large amounts, accelerating the separation of bulging from deformed parent grains to form DRX nuclei.

Shen et al. presented a new technology named extreme highspeed laser melting deposition (EHLMD). The deposition speed of this technology was as high as $30 \mathrm{~m} / \mathrm{min}$. AISI 431 martensitic layers of stainless steel were fabricated on 27SiMn substrates by conventional laser melting deposition (LMD) and extreme highspeed laser melting deposition. The corrosion resistance of the EHLMD layer was better than that of the LMD layer.

Cheng et al. carried out a study on self-developed CB10 steel. The mechanical properties of CB10 steel were the best at a tempering temperature of $450^{\circ} \mathrm{C}$ under the presented testing

\section{REFERENCES}

Chen, H. (2012). Application Manual of Wear-Resistant Materials, 2nd Edn. Beijing: China Machine Press, 10.

Padture, N. P., Gell, M., and Jordan, E. H. (2002). Thermal barrier coatings for gas-turbine engine applications. Science 296, 280-284. doi: 10.1126/science.1068609

Wei, S., and Xu, L. (2019). Review on research progress of steel and iron wearresistant material. Acta. Metall. Sin. 56, 523-538. doi: 10.11900/0412.1961.2019. 00370

Xu, L., Wei, S., Xiao, F., Zhou, H., Zhang, G., and Li, J. (2017). Effects of carbides on abrasive wear properties and failure behaviours of high speed steels with different alloy element content. Wear 376-377:968-974. doi: 10.1016/j.wear.2017.01.021 conditions. The CB10 steel possessed excellent anti-hydrogeninduced cracking performance and weldability. The maximum hardness and Charpy-absorbed energy of the heat-affected zone were $231 \mathrm{Hv}$ and $285.0 \mathrm{~J}$, respectively.

Li W. et al. investigated the coupling effect of lead and polishing treatments on the passive films of alloy 690TT in high-temperature and high-pressure water. The addition of lead caused a passive film to coat the mechanical polishing sample, and its thickness increased by eight times, while the electrochemically polished sample saw only a slight increase by comparison. It was suggested that the alloy 690TT showed the better performance when scratched in the secondary circuit system of pressurized water reactors. Besides, its scratched behavior would result in a faster corrosion rate of Alloy 690TT with the presence of lead.

Through these papers, the Research Topic has provided an overview of some promising advances in current research into wear-resistant materials. We sincerely hope that the Research Topic will provide a crossover study platform for the investigators and readers who are engaged with research into wear-resistant materials, and we also wish that this may promote the rapid development of wear-resistant materials.

\section{AUTHOR CONTRIBUTIONS}

All authors listed have made a substantial, direct and intellectual contribution to the work, and approved it for publication.

\section{FUNDING}

This work was also supported by National Natural Science Foundation of China (51771143, U1704152), the Program for Changjiang Scholars and Innovative Research Team (IRT1234), and the National Joint Engineering Research Center for Abrasion Control and Molding of Metal Materials (HKDNM201801).

\section{ACKNOWLEDGMENTS}

We would like to thank all the authors and reviewers who have supported this Research Topic.

Zhang, X. M., and Chen, W. P. (2015). Review on corrosion-wear resistance performance of materials in molten aluminum and its alloys. Trans Nonferrous Met Soc China 25, 1715-1731. doi: 10.1016/S1003-6326(15)63777-3

Conflict of Interest: The authors declare that the research was conducted in the absence of any commercial or financial relationships that could be construed as a potential conflict of interest.

Copyright $(5) 2020 \mathrm{Xu}, \mathrm{Ma}$ and Fu. This is an open-access article distributed under the terms of the Creative Commons Attribution License (CC BY). The use, distribution or reproduction in other forums is permitted, provided the original author(s) and the copyright owner(s) are credited and that the original publication in this journal is cited, in accordance with accepted academic practice. No use, distribution or reproduction is permitted which does not comply with these terms. 